\title{
Low dosage sulfite pretreatment at different refining temperatures in mill scale TMP production
}

\author{
Erik Nelsson, Magnus Paulsson, Christer Sandberg, Eva Svensson-Rundlöf and Per Engstrand
}

KEYWORDS: Double disc refining, Energy reduction, Norway spruce, Mill scale, Refining temperature, Sulfite pretreatment, TMP, Pulp properties

SUMMARY: The effects of low dosage sodium sulfite $\left(\mathrm{Na}_{2} \mathrm{SO}_{3}\right)$ pretreatment $(0,0.6$ and $1.2 \%$ on bone dry wood, $\mathrm{pH} 9)$ at two different refining temperatures (4.6 and $6.4 \mathrm{bar}(\mathrm{g})$ refiner housing pressure) were evaluated for production of thermomechanical pulp with a double disc refiner in mill scale using Norway spruce wood at Braviken paper mill (Holmen Paper AB, Sweden). The sulfonate content of the pulps was not affected by the different refining temperatures and was $0.29 \%$ (as $\mathrm{Na}_{2} \mathrm{SO}_{3}$ equivalents) for the highest sulfite addition.

Tensile index at constant SEC was increased by 3.2 $\mathrm{Nm} / \mathrm{g}$ when the refining temperature was increased, and by $8.6 \mathrm{Nm} / \mathrm{g}$ when $1.2 \%$ sodium sulfite was added. The effects were additive and led to an increase in tensile index of $\sim 12 \mathrm{Nm} / \mathrm{g}$ at constant SEC when combined and would enable a reduction in SEC of $380 \mathrm{kWh} / \mathrm{bdt}(\sim 20 \%)$ to similar tensile index. The degree of delamination and internal fibrillation of the fibers was increased by both increased refining temperature and sulfite addition.

Pulp brightness was slightly reduced $(\leq 0.4 \%$ ISO) by increased refining temperature and increased (2-3\% ISO), when sodium sulfite was added. Spectra of reflectance factors (360-740 nm) were used to study the optical properties of produced pulps.

ADDRESSES OF THE AUTHORS: Erik Nelsson (erik.nelsson@holmen.com), Holmen AB, Strandvägen 1, 11484 Stockholm, SWEDEN, Magnus Paulsson (magnus.paulsson@akzonobel.com), Akzo Nobel Pulp and Performance Chemicals AB, 44580 Bohus, SWEDEN and FSCN, Mid Sweden University, 85170 Sundsvall, SWEDEN, Christer Sandberg (christer.sandberg@holmenpaper.com), Eva SvenssonRundlöf (eva.svensson-rundlof@holmenpaper.com) Holmen Paper AB, 60188 Norrköping, SWEDEN, Per Engstrand (per.engstrand@miun.se), FSCN, Mid Sweden University, 85170 Sundsvall, SWEDEN Corresponding author: Erik Nelsson

Thermomechanical pulp (TMP) offers suitable pulp properties for the production of printing grade papers where optical properties and strength are important paper properties (Höglund, Wilhelmsson 1993). For this purpose, it is desirable to produce pulp with high enough tensile strength, light scattering and brightness. However, these properties are usually positively correlated with the specific energy consumption (SEC) in the TMP-process (McDonald et al. 2004). In order to increase tensile strength, light scattering and brightness without affecting SEC or to reduce SEC without affecting these pulp properties negatively, it is important to study the effect of different process parameters, e.g. conditions that have an influence on wood softening.
Wood softening is related to the transition of lignin from a brittle glass-like to an elastic rubber-like form, which occurs as the temperature is increased (Irvine 1985). Another way to increase wood softening is through chemical modification of lignin, e.g. by sulfonation, which will promote the transition of lignin to the more elastic form at lower temperatures (Atack et al. 1978). Becker et al. (1977) related the temperature for wood softening to the modulus and internal friction of wood and postulated that the optimal refining temperature should be found where the viscoelastic energy absorption is highest, at the maximum of modulus $\times$ internal friction. Furthermore, Becker et al. (1977) showed that the optimal refining temperature is dependent on refining frequency and is increased by $12^{\circ} \mathrm{C}$ when the frequency is increased by one order of magnitude in the longitudinal direction. Later, Salmén and Fellers (1982) suggested that the correlation between refining efficiency and the temperature for maximum viscoelastic energy absorption proposed by Becker et al. (1977) could have been a coincidence and that the temperature for maximum viscoelastic energy absorption instead may have offered a good compromise between the optimal temperatures for defibration and fibrillation. Salmén and Fellers (1982) found support for, that the optimal refining temperature for fibrillation was much higher than the optimal refining temperature for defibration.

Höglund et al. (1997) suggested a two stage refining process with increased preheating and refiner housing temperature $\left(160-170^{\circ} \mathrm{C}\right)$ in the second stage, where fibrillation was performed at higher temperature than defibration. This process reduced the energy consumption with about $20 \%$ when compared with a traditional TMP process where the second stage refining stage was performed at $115^{\circ} \mathrm{C}$ (Höglund et al. 1997). The reduction in disc gap, due to the higher temperature in the second stage refiner has been described as an important factor for the reduction in energy consumption (Höglund et al. 1997). However, the higher temperature also led to a reduction in brightness of 1-2 units (\% ISO) due to an increase in the light absorption coefficient (Höglund et al. 1997; Norgren et al. 2004).

Sabourin et al. (1997) reduced the retention time for chip preheating to 13 seconds, while at the same time increasing preheating and refiner housing temperature (5.9 bar(g)) and disc speed (2600 rpm) for first stage refining in pilot scale. This process modification enabled an energy reduction of $\sim 22 \%$ at maintained strength and optical properties, when compared to the traditional TMP process with 3 minutes preheating and refining at 2.8 $\operatorname{bar}(\mathrm{g})$ at $1800 \mathrm{rpm}$. The study showed the importance of using a short preheating time when refining at elevated pressures in order to preserve both the light scattering coefficient and the pulp strength (Sabourin et al. 1997). 
Sulfonation is another way to increase wood softening without reducing the pulp brightness (Atack et al. 1978; Axelson, Simonson 1982; Nelsson et al. 2015). Atack et al. (1978) studied wood blocks of black eastern spruce in the sulfonate content range 0.3 to $2.8 \%$ (as $\mathrm{Na}_{2} \mathrm{SO}_{3}$ equivalents) and found that the wood softening temperature was decreased by about $2{ }^{\circ} \mathrm{C}$ for every $0.1 \%$ increase in sulfonate content (as $\mathrm{Na}_{2} \mathrm{SO}_{3}$ equivalents). Johansson et al. (1997) studied lower degrees of sulfonation of wood blocks and found that a sulfonate content of $0.19 \%$ (as $\mathrm{Na}_{2} \mathrm{SO}_{3}$ equivalents) reduced the sheer stress by $5 \%$ and the failure energy by $10 \%$ when compared to samples with only water impregnation. Furthermore, in a recent study, Engberg et al. (2014) showed that a low degree of sulfonation at $\mathrm{pH} 9$ also resulted in wood softening when measured on small wood blocks at strain rates relevant for refining by using a Split-Hopkinson device. Axelson and Simonson (1982) studied mild sulfonation of wood chips in refining and found a maximum in tensile index and light scattering at constant SEC at sulfonate content of $0.2 \%$ (as $\mathrm{Na}_{2} \mathrm{SO}_{3}$ equivalents). Axelson and Simonson (1982) suggested that the more energy efficient refining was a result of a suitable decrease in wood softening temperature in relation to the temperature and frequency of the breaker bar section and the refining zone of the refiner used in their study.

Another explanation to the maximum in both tensile index and light scattering coefficient at a sulfur content of $0.2 \%$ (as $\mathrm{Na}_{2} \mathrm{SO}_{3}$ equivalents) may be that the primary cell wall is sulfonated selectively when low sulfite dosages are used (Westermark et al. 1987). Mild sulfonation has different effects on the softening temperature of the middle lamella and primary cell wall layer. The softening temperature of the primary cell wall layer is increased from a value below that of the middle lamella by sulfonation, whereas the softening temperature of the middle lamella is decreased (Östberg, Salmén 1988). A higher protein content in the primary cell wall layer may explain the different effects (Östberg, Salmén 1988). Johansson et al. (1997) compared the microscopic appearance of fiber-fiber fractures for wood with different sulfonate contents and were able to relate fiber surfaces where the middle lamella was almost completely removed to a sulfonate content of $0.2 \%$ (as $\mathrm{Na}_{2} \mathrm{SO}_{3}$ equivalents). These surfaces also had very thin, threadlike fragments which were not present at higher sulfonation levels (Westermark et al. 1987; Johansson et al. 1997).

Through the years, several studies have been performed to investigate the individual effect of wood softening through increased refining temperature or through sulfonation. However, to our knowledge the effect of refining temperature in combination with mild sulfonation has not earlier been thoroughly investigated using a mill scale refiner for the production of thermomechanical pulp intended for printing grade papers. In this study, the effect of increased wood softening through increased refining temperature in combination with mild sulfonation is studied and the effect on refiner parameters and pulp properties is thoroughly described.

\section{Materials and Methods}

A mill scale trial was conducted in the double disc TMP line (production rate 720 bone dry metric ton per day (bdt/d)) at the Braviken mill (Holmen Paper AB, Norrköping, Sweden). The raw material used was a mixture of $50 \%$ round wood and $50 \%$ saw mill chips from Norway spruce (Picea abies (L.) Karst.).

After presteaming and washing, chips were fed into the first atmospheric preheater $\left(90^{\circ} \mathrm{C}, 15 \mathrm{~min}\right.$.) and thereafter further preheated at $1.8 \mathrm{bar}(\mathrm{g})$ for a few seconds before compression in an Impressafiner (MSD500, Andritz), using $15 \mathrm{kWh} / \mathrm{bdt}$, Fig 1 . During the following impregnation, different dosages of sodium sulfite $\left(\mathrm{Na}_{2} \mathrm{SO}_{3}\right)$ were added with the impregnation liquid $(0.67$ $\mathrm{m}^{3} /$ bdt) at $\mathrm{pH} 9$ by mixing $\mathrm{NaHSO}_{3}$ and $\mathrm{NaOH}$ into the fresh water used for impregnation. The temperature of chips leaving the impregnator was $87^{\circ} \mathrm{C}$ and the retention time in the following second atmospheric preheater (no steam added) was $\sim 8$ minutes. Thereafter, chips were fed through a plug screw to the pressurized refiner feeding system where they were preheated at $4.8 \mathrm{bar}(\mathrm{g})\left(\sim 157^{\circ} \mathrm{C}\right)$ or $6.5 \operatorname{bar}(\mathrm{g})\left(\sim 168^{\circ} \mathrm{C}\right)$ for $\sim 8$ seconds prior to refining. The pressurized refiner feeding system was supplied with 4.5-7.1 ton/h steam from the $12 \mathrm{bar}(\mathrm{g})$ steam supply. The refiner housing pressure was $4.6 \mathrm{bar}(\mathrm{g})\left(\sim 156^{\circ} \mathrm{C}\right)$ or 6.4 $\operatorname{bar}(\mathrm{g}) \quad\left(\sim 167^{\circ} \mathrm{C}\right)$ respectively. The refiner housing pressure was controlled by the blow line valve (after the refiner) and the addition of steam to the refiner feeding system. The pressure drop over the refiner was $0.10-0.15$ bar. Refining was performed in a double disc refiner, RGP68DD (Valmet), counter-rotating at $2 \times 1500 \mathrm{rpm}$ with 72" Low shive segments (Valmet, p-N72N816-817 and c-DO52B036-037). The consistency of the blow line pulps was $28-33 \%$. Disc gap and disc gap temperature was measured with a TDC sensor (Valmet) located a radius of $810 \mathrm{~mm}$ in the refiner.

Pulp samples were collected from the blow line directly after the double disc refiner for each setting of refining energy (1700-2160 kWh/bdt), refining housing pressure (4.6 and $6.4 \operatorname{bar}(\mathrm{g})$ ) and dosages of $\mathrm{Na}_{2} \mathrm{SO}_{3}(0,0.6$ and $1.2 \%$ on bone dry wood). Five pulp samples were collected during 15 minutes and thereafter mixed to produce a composite sample for each process setting. The refiner production rate was $9.2 \mathrm{bdt} / \mathrm{h}$. The specific energy of the specific electrical energy consumption of consumption is presented as "total SEC" which is the sum compression prior to impregnation $(\sim 15 \mathrm{kWh} / \mathrm{bdt})$ and refining (1700-2160 kWh/bdt).

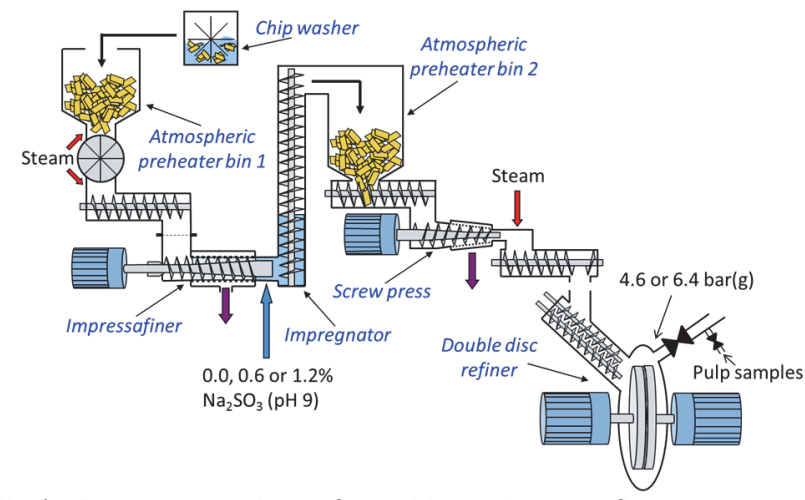

Fig 1 - Process overview - from chip washer to refiner. 
Pulp samples were analyzed with the following methods/instruments: Hot disintegration (ISO 5263-3), fiber length and shives content (PulpEye, PulpEye AB, Sweden), Canadian standard freeness (ISO 5267-2), Rapid Köthen lab sheet (ISO 5269-2, DIN 54358), density (ISO 534), tensile index (ISO 1924-2), tear index (ISO 1974), sulfur content (SCAN-CM 57:99), brightness (ISO 2470) and spectral measurements (360-740 nm) of $R_{0}$ and $R_{\infty}$ (Minolta CM-3630). The light scattering and absorption coefficients were calculated from the diffuse reflectance factors $R_{0 \lambda}$ and $R_{\infty \lambda}$ using the Kubelka-Munk model (Kubelka, Munk 1931; Kubelka 1948) according to ISO 9416.

The internal fiber development was measured according to Fernando and Daniel's (2010) method of Simons' staining. Ten grams (bone dry) of each pulp was washed with $10 \times 1$ liters of water in a Britt dynamic drainage jar (BDDJ) using a 30 mesh wire to remove fines prior to the Simons' staining measurement. Two hundred fibers from each pulp were classified in three categories: none, low and high degree of delamination and internal fibrillation $(\mathrm{D} / \mathrm{IF})$ of the fibers.

The sulfonate content was determined for two types of pulp samples: 1) For pulps directly after sampling: 200 gram of the pulp was immediately submerged in 10 liter of cold water after collection from the blow line in order to stop further sulfonation, the pulps were then dewatered and dried before analysis; 2) For pulps used for producing lab sheets: these pulps were not cooled after sample collection, but after hot disintegration, pulps were dewatered and dried before analysis.

\section{Results and discussion}

Chips were impregnated with low dosages of sodium sulfite $(0.0,0.6$ and $1.2 \%$ on bone dry wood) and refined at two different temperatures (refiner housing pressures of 4.6 and $6.4 \mathrm{bar}(\mathrm{g})$, corresponding to refiner housing temperatures of 156 and $167^{\circ} \mathrm{C}$ ) to freeness $60-260 \mathrm{~mL}$ in a modern mill scale single stage double disc refiner.

\section{Sulfonate content}

The sulfonate contents of pulps that were cooled down directly after sample collection (to stop further reaction), was $0.10 \%$ as $\mathrm{Na}_{2} \mathrm{SO}_{3}$ equivalents $(7.9 \mu \mathrm{mol} / \mathrm{g}, 0.063 \%$ $\mathrm{SO}_{3}^{-}$) when charging $0.6 \%$ sodium sulfite and $0.23 \%$ as $\mathrm{Na}_{2} \mathrm{SO}_{3}\left(18.4 \mu \mathrm{mol} / \mathrm{g}, 0.15 \% \mathrm{SO}_{3}^{-}\right)$when charging $1.2 \%$ sodium sulfite. There was no sulfur present in pulps produced without sulfite addition and there was no difference in sulfonate contents between pulps produced at different refining temperatures. The sulfonate contents of pulps used to produce lab sheets (allowed to cool down in room temperature after sample collection) were $0.12 \%$ and $0.29 \%$ as $\mathrm{Na}_{2} \mathrm{SO}_{3}$ for the addition of $0.6 \%$ and $1.2 \%$ sodium sulfite, respectively, resulting in conversion ratio of about $23 \%$. The higher sulfonate contents for these pulps were a result of post-sulfonation.

\section{Refiner disc gap}

The disc gap temperature increased both when the refiner housing pressure/temperature was increased and when sodium sulfite was added to the chip impregnation, Fig 2. The increase in refiner housing pressure from 4.6 to 6.4 $\operatorname{bar}(\mathrm{g})$ corresponds to a temperature increase from 156 to $167^{\circ} \mathrm{C}$ for saturated steam in the refiner housing (outside the disc gap). The temperature in the disc gap was higher than that in the refiner housing, which is normal during refining and was probably a result of a restricted steam flow from the disc gap to the refiner housing. It should be noted that disc gap temperature was only measured in one position (at radius $810 \mathrm{~mm}$ ), and a change in temperature in this position could have been a result of an increase in temperature over the entire radius and/or a change in the radial position of the pressure peak.

Increasing the refiner housing pressure from 4.6 to 6.4 $\operatorname{bar}(\mathrm{g})$ increased the disc gap temperature with $6^{\circ} \mathrm{C}$, from 171.6 to $177.6^{\circ} \mathrm{C}$ when no sodium sulfite was added at a total SEC of $1900 \mathrm{kWh} / \mathrm{bdt}$, Table 1. The temperature increase corresponds to a pressure increase of 1.3 bar (for saturated steam), which was smaller than the pressure increase of 1.8 bar in the refiner housing. The difference can be explained by a lower production of steam in the disc gap at the higher pressure/temperature

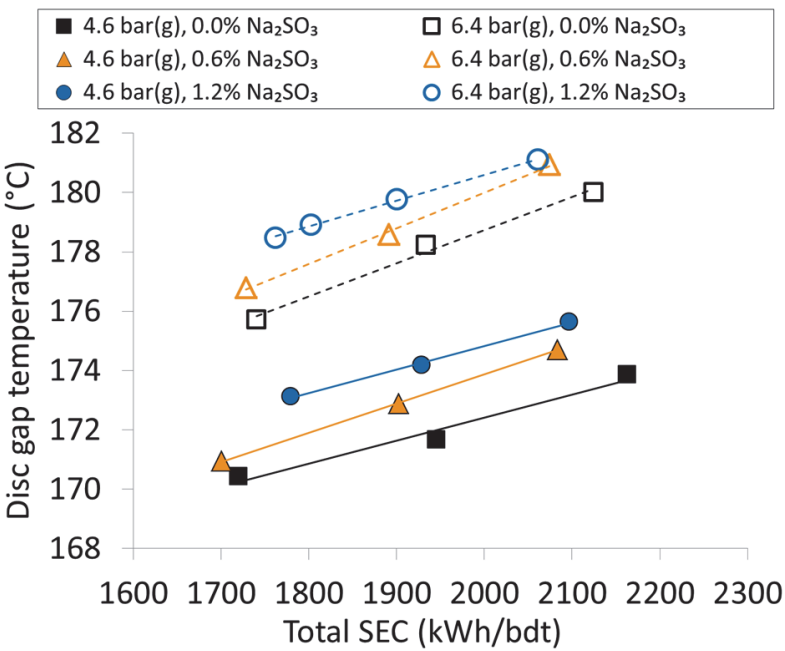

Fig 2 - Disc gap temperature at the radius of $810 \mathrm{~mm}$ (TDC sensor) vs. total specific energy consumption (SEC).

Table 1 - Refiner parameters at a total specific energy consumption of $1900 \mathrm{kWh} / \mathrm{bdt}$ for different refiner housing pressures and sodium sulfite doses.

\begin{tabular}{|c|c|c|c|c|}
\hline Sodium sulfite dosage, $\%$ & 0 & 0 & 1.2 & 1.2 \\
\hline Refiner housing press., bar(g) & 4.6 & 6.4 & 4.6 & 6.4 \\
\hline Refiner housing temp. ${ }^{a},{ }^{\circ} \mathrm{C}$ & 156 & 167 & 156 & 167 \\
\hline Refiner housing steam volumec & 354 & 275 & 354 & 275 \\
\hline Disc gap pressure ${ }^{a, b}$, bar $(g)$ & 7.2 & 8.5 & 7.7 & 9.0 \\
\hline Disc gap temperature ${ }^{b},{ }^{\circ} \mathrm{C}$ & 171.6 & 177.6 & 174.0 & 179.7 \\
\hline Disc gap steam volumec, $\mathrm{m}^{3} /$ ton & 249 & 219 & 236 & 210 \\
\hline $\begin{array}{l}\text { Pressure difference (disc gappa,b } \\
\text { - refiner housing), bar }\end{array}$ & 2.6 & 2.1 & 3.1 & 2.6 \\
\hline Disc gap ${ }^{b}, \mathrm{~mm}$ & 0.90 & 0.84 & 0.80 & 0.76 \\
\hline Hydraulic force, ton & 68 & 66 & 69 & 64 \\
\hline Refiner feeding press., bar(g) & 4.8 & 6.6 & 4.8 & 6.5 \\
\hline Steam to feeding system, ton/h & 4.5 & 6.8 & 5.9 & 7.1 \\
\hline Refiner dilution water, m³/h & 29 & 28 & 30 & 29 \\
\hline Blow line pulp consistency, \% & 33 & 29 & 32 & 28 \\
\hline
\end{tabular}

a)Calculated for saturated steam. b)At the radius of $810 \mathrm{~mm}$ (TDC sensor). ${ }^{c}$ Calculated for ideal gas ( $\mathrm{m}^{3} /$ ton) 
since a larger part of the refining energy was used to heat water and wood up to a higher boiling point. Another explanation may be that the lower volume of steam at higher pressure led to a more effective evacuation of steam from the disc gap into the refiner housing. The addition of 0.6 and $1.2 \% \mathrm{Na}_{2} \mathrm{SO}_{3}$ increased the disc gap temperature by about 1 and $2^{\circ} \mathrm{C}$, respectively, Fig 2 . The increase in disc gap temperature due to addition of sodium sulfite was similar at both refiner housing pressures.

In addition to an increase in disc gap temperature, the disc gap was also reduced by both increased refiner housing pressure and addition of sodium sulfite, Fel! Hittar inte referenskälla. and Table 1 . The addition of $0.6 \%$ sodium sulfite led to a similar reduction in disc gap as the increase in refiner housing pressure from 4.6 to 6.4 bar(g). The reduction in disc gap can be explained by softer fibers and lower steam volume at the higher temperature and pressure in the disc gap, cf. Table 1 (Höglund et al. 1997). The reduction in disc gap due to sulfonation can probably also explain the increase in disc gap temperature when sodium sulfite was added. The smaller disc gap restricted the steam flow in the disc gap and therefore increased both pressure and temperature in the disc gap, Table 1.

The pressure in, and steam flow to the pressurized refiner feeding system are presented in the bottom of Table 1. It was necessary to increase the steam flow to the refiner feeding system in order to reach the higher pressure (6.5-6.6 bar(g)). The increase in steam flow led an increase in condensation of steam in the refiner feeding system. This led to slightly lower consistencies for the blow line pulps produced at the higher refining pressure, when compared to pulps produced at the lower pressure Table 1.

\section{Strength properties}

Tensile index of pulps produced at constant SEC were increased both by increased refiner housing pressure and by addition of sodium sulfite, Fig $4 a$. The increase in refiner housing pressure (from 4.6 to 6.4 bar(g)) combined with addition of sodium sulfite (1.2\%) increased tensile index by $\sim 12 \mathrm{Nm} / \mathrm{g}$.

To accurately assess the individual effects of sulfite addition and refining temperature on tensile index, multiple linear regression was used to produce a statistical model, Appendix 1. Fig $4 b$ shows the model which had a good fit with measured values with an $r^{2}$ value of $96 \%$. There was no significant interaction effects between SEC, refiner housing pressure and sulfite addition on tensile index, which means that the effects were additive. From the model it was possible to extract the individual effect of each parameter on tensile index and to relate that effect to energy consumption, as shown in. The increase in tensile index of $\sim 12 \mathrm{Nm} / \mathrm{g}$, resulting from increased refiner housing pressure (from 4.6 to 6.4 $\operatorname{bar}(\mathrm{g}))$ and addition of sodium sulfite (1.2\%), corresponded to a reduction in SEC of $\sim 380 \mathrm{kWh} / \mathrm{bdt}$ to equal tensile index. An energy reduction of $380 \mathrm{kWh} / \mathrm{bdt}$ corresponded to $18 \%$ at the highest energy level $(\sim 2160$ $\mathrm{kWh} / \mathrm{bdt})$ and $22 \%$ at the lowest energy level $(\sim 1700$ $\mathrm{kWh} / \mathrm{bdt})$. The increase in tensile index was similar to the earlier reported results from this TMP line when increasing the refining temperature (Muhić et al. 2010) or adding sulfite (Nelsson et al. 2015) separately.

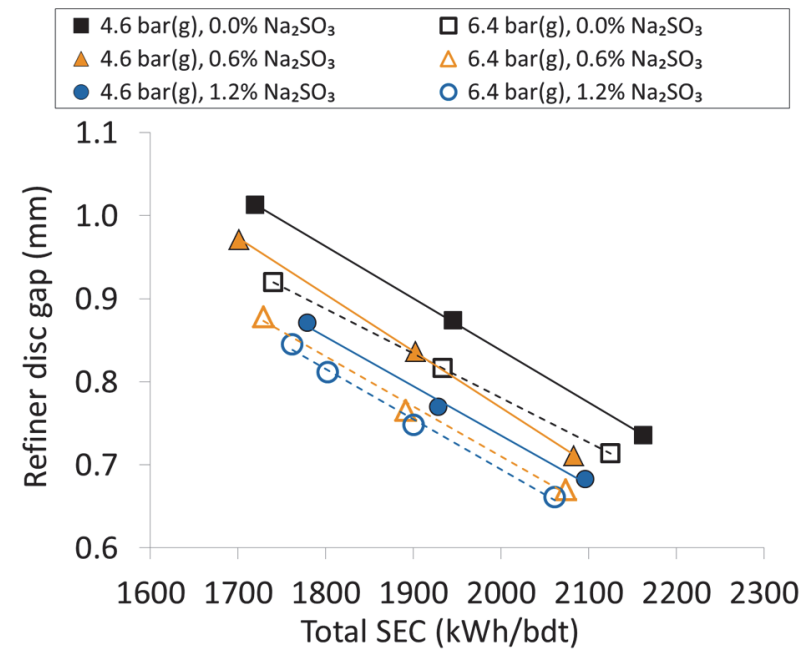

Fig 3 - Disc gap at the radius of $810 \mathrm{~mm}$ (TDC sensor) vs. total specific energy consumption (SEC).
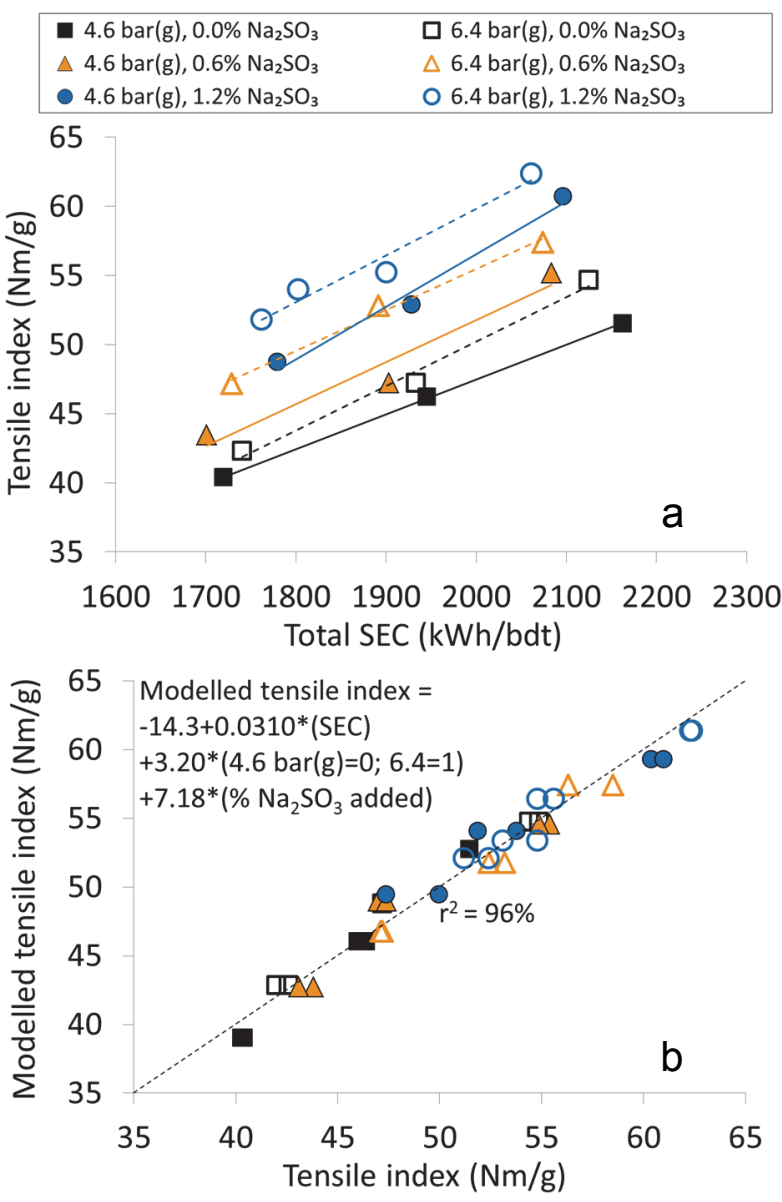

Fig 4 - (a) Tensile index vs. total specific energy consumption (SEC). (b) Measured tensile index vs. modelled tensile index as calculated by the equation shown in the figure (the statistic model can be found in Appendix 1). 
Table 2 - Response in tensile index to changes in process parameters (the statistic model can be found in Appendix 1).

\begin{tabular}{lccc}
$\begin{array}{l}\text { Process } \\
\text { parameter }\end{array}$ & $\begin{array}{c}\text { Change in } \\
\text { process } \\
\text { parameter }\end{array}$ & $\begin{array}{c}\text { Response in } \\
\text { tensile index } \\
\text { (Nm/g) }\end{array}$ & $\begin{array}{c}\text { Reduction in SEC } \\
\text { to equal tensile } \\
\text { index (kWh/bdt) }\end{array}$ \\
\hline $\begin{array}{l}\text { Total SEC } \\
100 \mathrm{kWh} / \mathrm{bdt}\end{array}$ & $3.1( \pm 0.27)$ & \\
$\begin{array}{l}\text { Refiner } \\
\text { housing } \\
\text { pressure }\end{array}$ & $\begin{array}{c}4.6 \text { to } 6.4 \\
\text { bar(g) }\end{array}$ & $3.2( \pm 0.8)$ & $100(70-150)$ \\
$\mathrm{Na}_{2} \mathrm{SO}_{3}$ & 0 to $1.2 \%$ & $8.6( \pm 0.99)$ & $280(220-340)$ \\
addition & & & \\
$\begin{array}{l}\text { Pressure } \\
\text { and sulfite }\end{array}$ & 4.6 to 6.4 & $11.8( \pm 1.78)$ & $380(290-490)$ \\
bombined & bar(g) \& 1.2\% & & \\
\hline
\end{tabular}

Values within parentheses: $\geq 95 \%$ confidence intervals.
\begin{tabular}{|ll|}
\hline $4.6 \mathrm{bar}(\mathrm{g}), 0.0 \% \mathrm{Na}_{2} \mathrm{SO}_{3}$ & $\square 6.4 \mathrm{bar}(\mathrm{g}), 0.0 \% \mathrm{Na}_{2} \mathrm{SO}_{3}$ \\
$44.6 \mathrm{bar}(\mathrm{g}), 0.6 \% \mathrm{Na}_{2} \mathrm{SO}_{3}$ & $\triangle 6.4 \mathrm{bar}(\mathrm{g}), 0.6 \% \mathrm{Na}_{2} \mathrm{SO}_{3}$ \\
$4.6 \mathrm{bar}(\mathrm{g}), 1.2 \% \mathrm{Na}_{2} \mathrm{SO}_{3}$ & $\bigcirc 6.4 \mathrm{bar}(\mathrm{g}), 1.2 \% \mathrm{Na}_{2} \mathrm{SO}_{3}$ \\
\hline 500
\end{tabular}
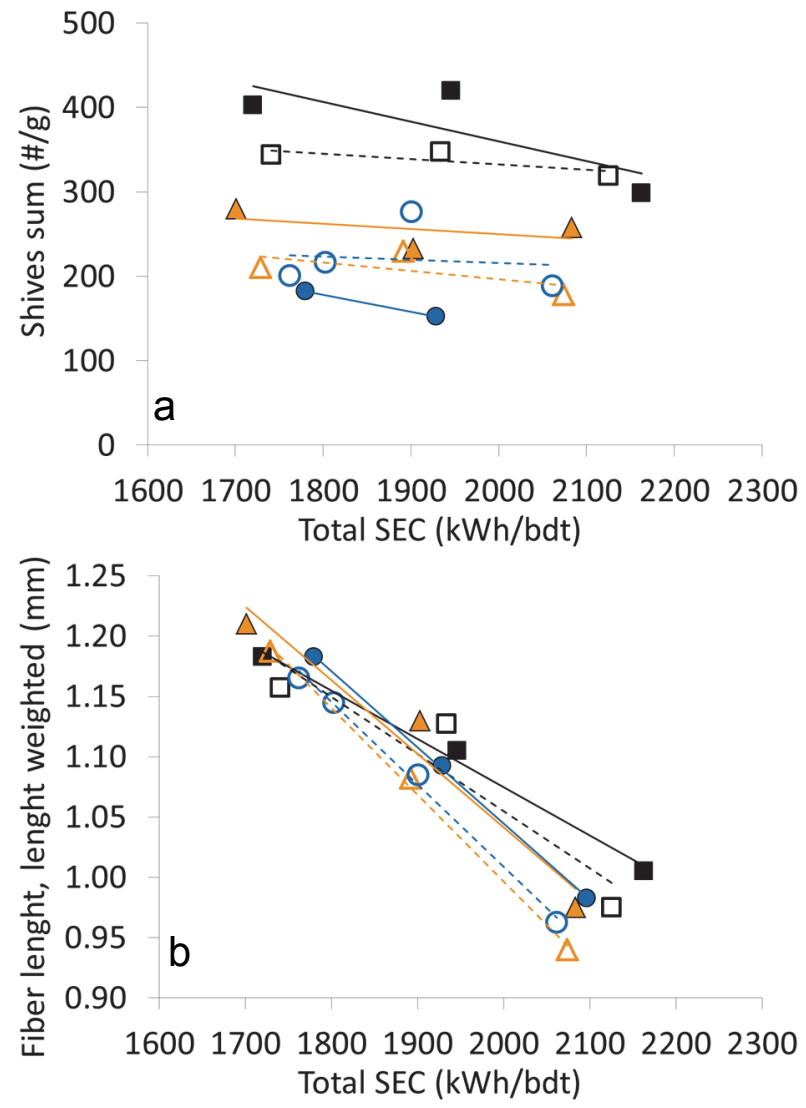

Fig 5 - (a) Shives sum (PulpEye) and (b) length weighted fiber length (PulpEye) vs. total specific energy consumption (SEC).

\section{Fiber properties}

The amount of shives in blow line pulps was effectively reduced when sodium sulfite was added, Fig $5 a$. Shives levels were reduced by approximately $50 \%$ when compared at equal SEC. The increase in refiner housing pressured did not significantly affect the shives content.

The fiber length was reduced by approximately $0.1 \mathrm{~mm}$ at the highest refining energy level ( 2160 kWh/bdt) when the refiner housing pressure was increased and sodium sulfite added, Fig $5 b$. This was probably caused by the reduction in disc gap; more severe fiber shortening
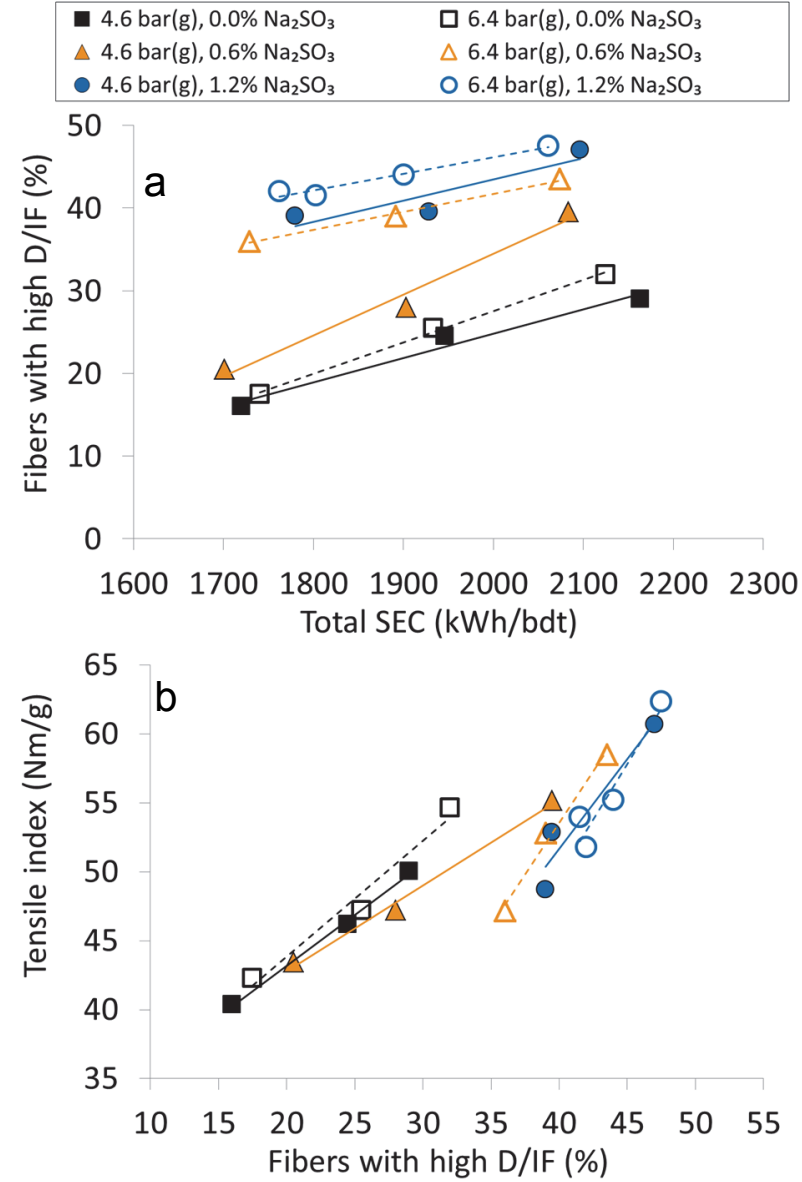

Fig 6 - (a) Percentage of fibers (BDDJ, >30 mesh) with high degree of delamination and internal fibrillation (D/IF) vs. total specific energy consumption (SEC). (b) Tensile index vs. percentage of fibers (BDDJ, $>30$ mesh) with high D/IF.

occurred at the lowest disc gaps. However, when compared at a constant tensile index, fiber length was increased by both increased refiner housing pressure and sodium sulfite addition. The tear index at constant tensile index was not affected by an increased refiner housing pressure or addition of sodium sulfite, data not shown.

Simon's staining was performed on the fiber fraction (BDDJ, >30 mesh) of all pulps in order to determine the degree of delamination and internal fibrillation (D/IF) of the fibers (Fernando, Daniel 2010). The percentage of fibers with high $\mathrm{D} / \mathrm{IF}$ is here used as an indicator for the degree of internal fiber development. Simons' staining measures accessibility of the interior surfaces in fiber cell walls through selective staining of fibers containing pores larger than $5 \mathrm{~nm}$ ( $\mathrm{Yu}$ et al. 1995). Internal fiber development (i.e. wall D/IF) has earlier been shown to correlate positively with fiber flexibility and whole pulp tensile index (Stone et al. 1968; Fernando et al. 2011; Fernando et al. 2013; Nelsson et al. 2015).

All three process parameters studied (SEC, refining temperature and sodium sulfite addition) had an effect on the degree of D/IF. Higher SEC, refining temperature and sodium sulfite addition led to higher percentage of fibers with high D/IF. Similar results for the effects of SEC and refining temperature (Fernando et al. 2011) and of SEC and sodium sulfite addition (Nelsson et al. 2015) on D/IF have been published earlier. However, this study is the 
first where the effects of SEC, refining temperature and sodium sulfite addition on D/IF have been measured for the same data set. The effects of the studied parameters on D/IF are shown in Fig $6 a$. The pulps produced with $1.2 \%$ sodium sulfite and the pulps produced with $0.6 \%$ sodium sulfite at high refiner housing pressure had higher percentage of fibers with high D/IF compared to the other pulps at similar SEC.

As expected from previous studies (Fernando et al. 2011; Nelsson et al. 2015), tensile index of whole pulps correlated with the percentage of fibers with high D/IF, Fig $6 b$. The correlation had an $\mathrm{r}^{2}$-value of $80 \%$, which was similar to that obtained in earlier studies (Fernando et al. 2011; Nelsson et al. 2015). The correlation gives further support for the hypothesis earlier proposed by Nelsson et al. (2015), that an increased fiber flexibility and collapsibility, seen as an increased percentage of fibers with high $\mathrm{D} / \mathrm{IF}$, is an important factor for the increased tensile index of mildly sulfonated pulps.

\section{Optical properties}

The brightness increased 2-3\% ISO by addition of sodium sulfite and was slightly reduced $\leq 0.4 \%$ ISO by increased refiner housing pressure, Fig $7 a$. The changes were primarily caused by changes in the light absorption coefficient, $k_{460}$, which was slightly increased by increased refining temperature and decreased by addition of sodium sulfite, Fig $7 b$. The light scattering coefficient, $S_{460}$, was not significantly affected by an increased refining temperature for non-sulfonated pulps, Fig $7 c$. However, when sodium sulfite was added, there was a lager difference in light scattering between pulps produced with different refiner housing pressures, with higher light scattering coefficient for the pulps produced with the higher pressure, when compared at similar SEC. The pulp produced with $0.6 \%$ sodium sulfite addition at the higher refiner housing pressure using $\sim 1900 \mathrm{kWh} / \mathrm{bdt}$ had similar light scattering coefficient and $2 \%$ ISO higher brightness compared with the reference pulp, produced without sulfite using the lower pressure at similar SEC. There was a decreased in $s_{460}$ for the pulps with the highest sodium sulfite dosage (1.2\%) and the low refiner housing pressure $(4.6 \mathrm{bar}(\mathrm{g}))$. However, the measurement error for the pulp $(1.2 \%, 4.6 \operatorname{bar}(\mathrm{g}))$ with the highest SEC was large which may have influenced the 5460 -value for this pulp.

Kubelka-Munk modeling was used to calculate $s_{\lambda}$ and $k_{\lambda}$ from the reflectance factors $R_{0 \lambda}$ and $R_{\infty \lambda}$ in the wavelength region 360-720 nm. It was not possible to calculate reliable values for $s_{\lambda}$ and $k_{\lambda}$ below $440 \mathrm{~nm}$ due to strong light absorption at these wavelengths, which is known to give incorrect $s_{\lambda}$ and $k_{\lambda}$ values (cf. Rundlöf, Bristow 1997; Karlsson et al. 2012). The intrinsic reflectance factor $R_{\infty \lambda}$ was therefore primarily used to identify the effects of sulfonation and refiner housing pressure. In order to remove the effect of difference in SEC between different pulps, the values for $R_{0 \lambda}, R_{\infty}, s_{\lambda}$ and $k \lambda$ were interpolated to $1900 \mathrm{kWh} / \mathrm{bdt}$ (at each measured wavelength). These values were then used to calculate the delta values shown in Fig $8 b, c$ and $e-h$. The intrinsic reflectance factor $R_{\infty}$, Fig $8 a$, had a normal shape for mechanical pulps, with low values at shorter wavelengths due to high light absorption at these wavelengths originating from chromophores in lignin (Norrström 1969; Hon, Glasser 1979).

The effect of sodium sulfite addition on $R_{\infty \lambda}$ was isolated in Fig 8b, where spectra for pulps produced without sodium sulfite addition was subtracted from spectra of pulp with different sulfite additions at the two different refiner pressures. Addition of $0.6 \%$ sodium sulfite gave a broad peak in the spectrum with a maximum at $490-500 \mathrm{~nm}$, independently of refiner housing pressure. Since the s-values were lower for the
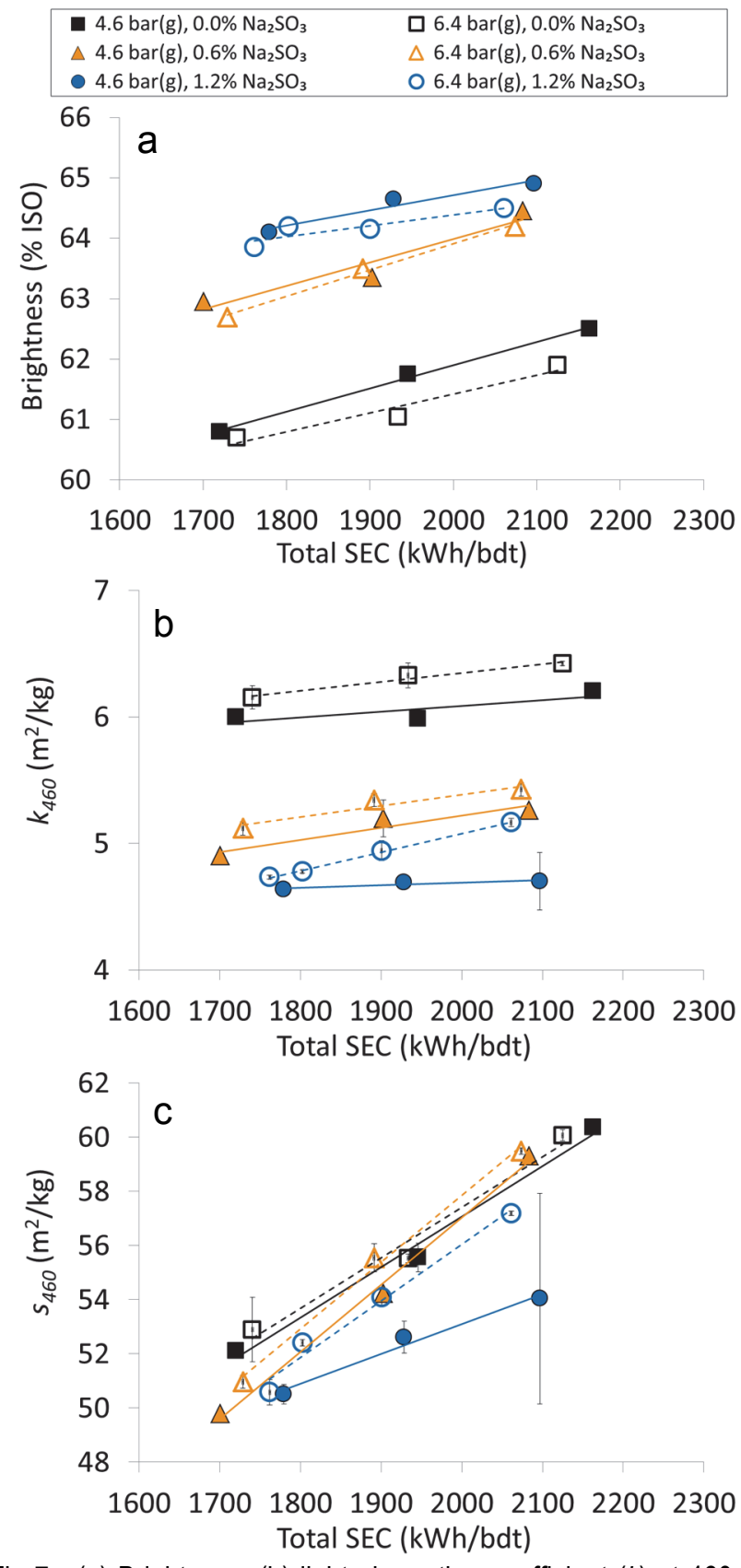

Fig 7 - (a) Brightness, (b) light absorption coefficient (k) at 460 $\mathrm{nm}$ and (c) light scattering coefficient $(s)$ at $460 \mathrm{~nm}$ vs. total specific energy consumption (SEC). Error bars in (b) and (c) shows measurements from two different set of lab sheets that were used to calculate the average value for the data points. Some error bars are hidden behind its data point. 

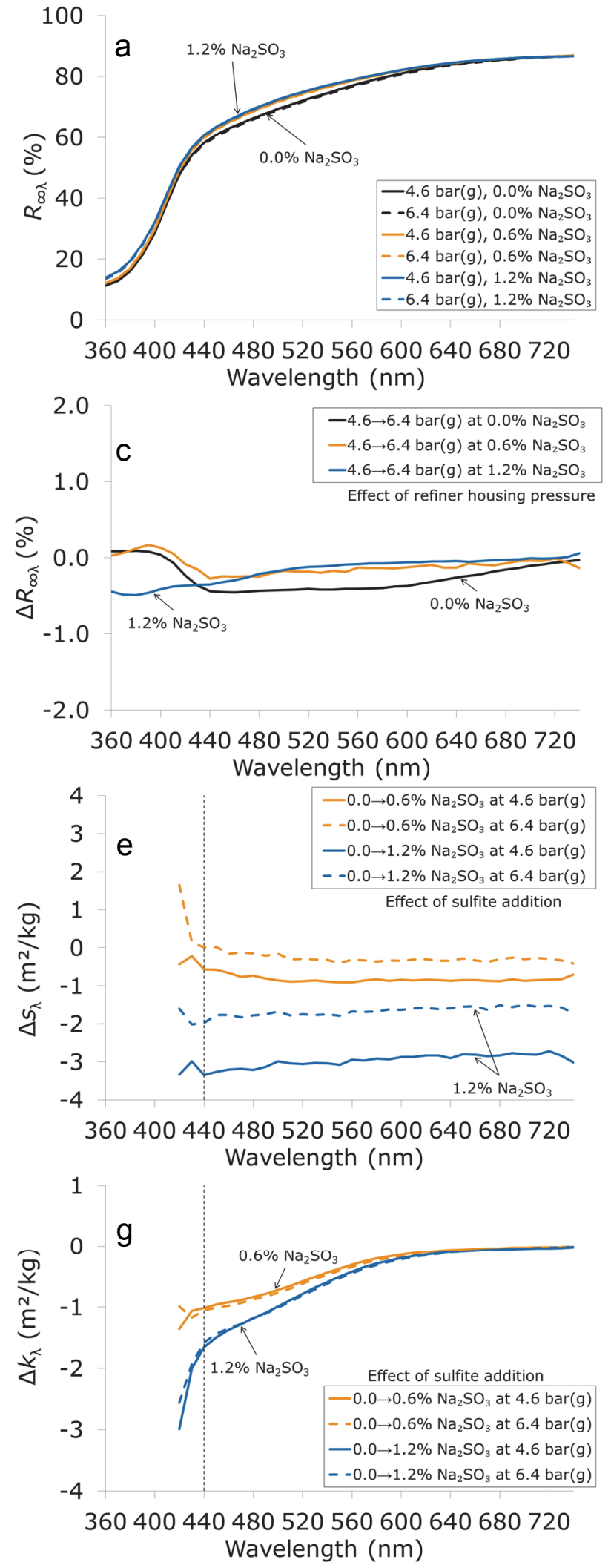

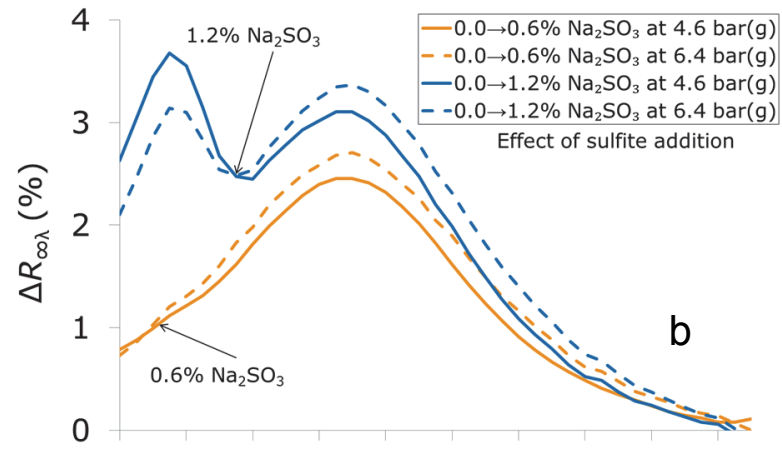

360400440480520560600640680720 Wavelength $(\mathrm{nm})$

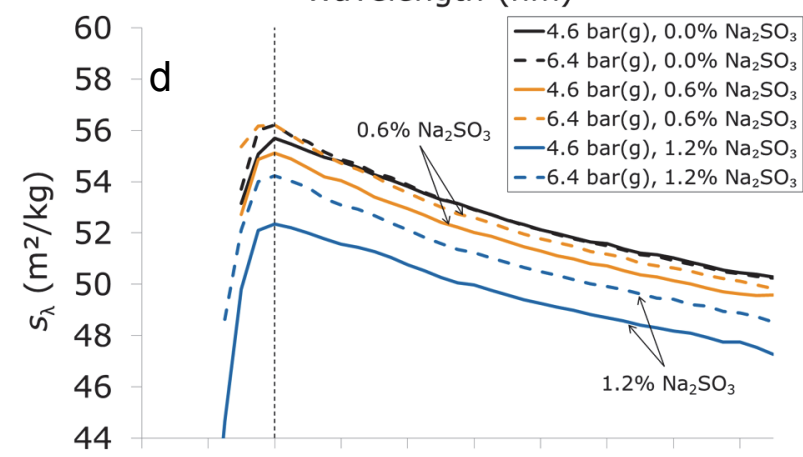

360400440480520560600640680720 Wavelength $(\mathrm{nm})$

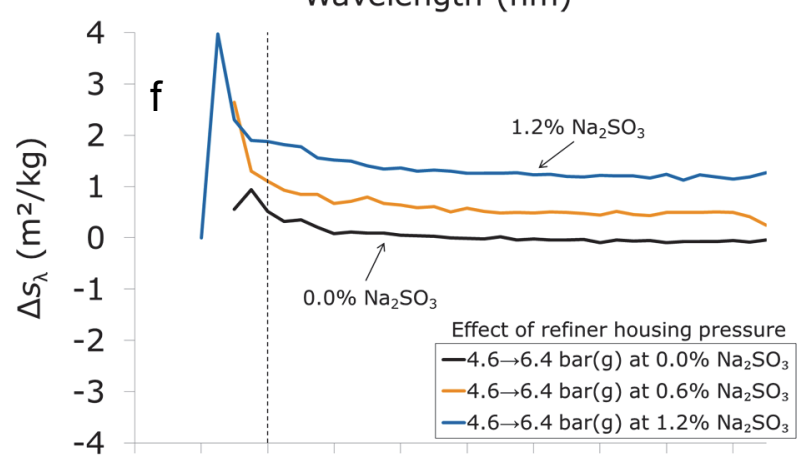

360400440480520560600640680720 Wavelength $(\mathrm{nm})$

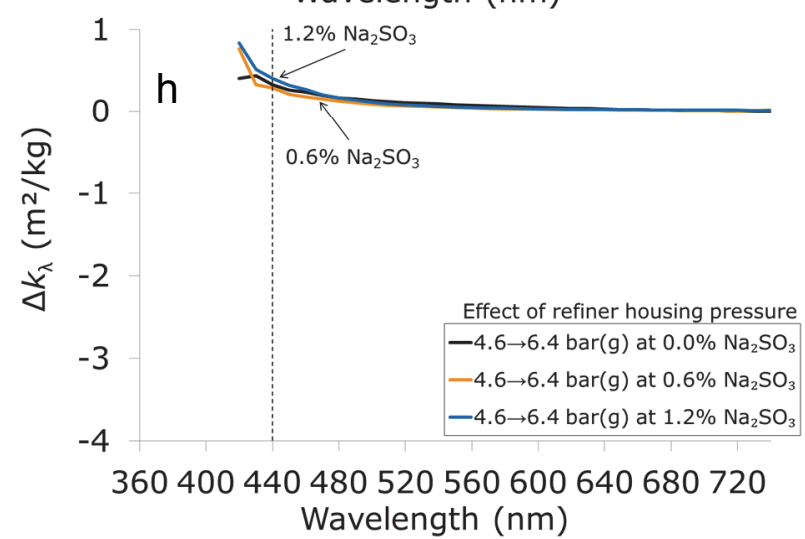

Fig 8 - Spectral data for unsulfonated and sulfonated ( 0.6 and $1.2 \%$ sodium sulfite added) pulps produced at two refiner housing pressures (4.6 and 6.4 bar(g)). The values for $s_{\lambda}$ and $k_{\lambda}$ below $440 \mathrm{~nm}$ (marked with dotted lines) were unreliable due to too strong

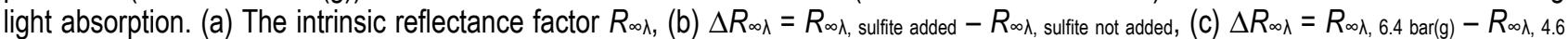

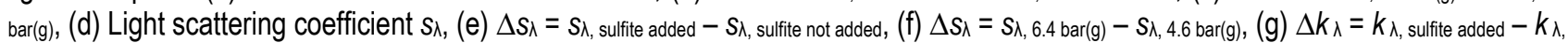
sulfite not added, (h) $\Delta k_{\lambda}=k_{\lambda, 6.4 \mathrm{bar}(\mathrm{g})}-k_{\lambda, 4.6 \mathrm{bar}(\mathrm{g}) \text {. }}$ 
pulps produced with sodium sulfite, and the spectra for $\mathrm{s}_{\lambda}$, Fig $8 d$ and $e$, were linear at these wavelengths, it is safe to assume that the increase in $R_{\infty \lambda}$, the peak at 490-500 $\mathrm{nm}$, is a result of a reduction in $k_{\lambda}$, Fig $8 g$, resulting from removal of chromophores with absorption maxima in this region.

One type of chromophore that can be affected by sulfonation are substituted ortho-quinones (Gellerstedt 2009), that have maximum absorption at wavelengths around $500 \mathrm{~nm}$ in solid-state (Zhang, Gellerstedt 1998). When the sodium sulfite dosage was increase to $1.2 \%$, the peak at 490-500 nm increased and a new peak at 390 $\mathrm{nm}$ emerged in the difference spectrum, Fig $8 b$. Under the prerequisite that $s_{\lambda}$ continues in a linear manner for wavelengths below $440 \mathrm{~nm}$, the peak at $390 \mathrm{~nm}$ could be associated with the removal of coniferaldehyde chromophores that absorb light around $400 \mathrm{~nm}$ in solid state (Gellerstedt 2010). Further, para-quinones have absorption maxima close to $400 \mathrm{~nm}$ in solid-state (Gellerstedt 2010) and these structures are known to react with bisulfite/sulfite (Lundquist et al. 2007).

It should be noted that an increase in the intrinsic reflectance factor due to addition of sodium sulfite, $\Delta R_{\infty \lambda}$ in Fig $8 b$, is not direct proportional to the light absorption of removed chromophores. The removal of chromophores with a certain amount of light absorption will result in a much larger $\Delta R_{\infty \lambda}$ at wavelengths where $R_{\infty \lambda}$ of the reference pulp is high. Hence, the maximum at $390 \mathrm{~nm}$ for $\Delta R_{\infty \lambda}$, when $1.2 \%$ sodium sulfite was added, is associated with removal of chromophores with a larger amount of light absorption than for the maximum at 490$500 \mathrm{~nm}$, despite the similar height of these maxima, Fig $8 b$. This explains why there was no apparent, corresponding minimum for $\Delta k_{\lambda}$ at $490-500 \mathrm{~nm}$, since this location is at the beginning of the much larger minimum, corresponding to the maximum in $\Delta R_{\infty \lambda}$ at $390 \mathrm{~nm}$. However, the slope of $\Delta k_{\lambda}$ around 490-500 nm indicate the existence of a concealed minimum which becomes visible when studying the first derivate of $\Delta k_{\lambda}$.

The effect of increased refiner housing pressure on the optical spectra of pulps was small compared to the effect of adding sodium sulfite, Figs $8 c, f$ and $h$. The effects were an increase in $\Delta s \lambda$ when the refiner housing pressure was increased for pulps produced with 0.6 and $1.2 \%$ addition of sodium sulfite, Fig $8 f$, and a slight increase in $\Delta k_{\lambda}$ when the refiner housing pressure was increased, Fig $8 h$. This resulted in a slightly larger reduction in $\Delta R_{\infty} \lambda$ when the refiner housing pressure was increased without addition of sodium sulfite, compared with pulps produced with sodium sulfite addition, Fig $8 c$.

\section{Final comments}

Both increased refiner housing pressure and sulfite addition increased wood softening and tensile index of pulps at certain SEC. There was however some differences in the effect on other pulp properties when using the two different methods to increase wood softening. Addition of sodium sulfite reduced the shives content and slightly decreased the light scattering coefficient at certain SEC while increase in refiner housing pressure did not significantly affect these pulp properties. An explanation for this may be that the sulfite addition increased the degree of wood softening prior to the breaker bar zone in the refiner more compared to when the refiner housing pressure was increased. Chips were preheated in the double disc feeding system for $\sim 8$ $\mathrm{sec}$ at $11^{\circ} \mathrm{C}$ higher temperature $\left(168\right.$ vs $\left.157^{\circ} \mathrm{C}\right)$ when the higher refiner housing pressure was used. At the end of the feeding system, just before chips enter the refiner, a large amount of dilution water at a temperature of $35^{\circ} \mathrm{C}$ was added. Due to the short preheating time and the large amount of relatively cool water added, the temperature of chips entering the breaker bar zone may not have been much higher when 6.4 bar(g) was used as refiner housing pressure compared with when 4.6 bar(g) was used. However, in the refining zone, pulp was heated to about $6^{\circ} \mathrm{C}$ higher temperature when the higher refiner housing pressure was used. This temperature difference was enough to increase the degree of wood softening in the outer part of the refining zone which, in combination with the lower steam volume, led to a reduction in the disc gap and probably to more intense refining at certain SEC. Another difference between using increased refiner housing pressure or sulfite addition to increase wood softening was the effect on pulp brightness. The brightness increased 2-3\% ISO by addition of sodium sulfite and was slightly reduced $\leq 0.4 \%$ ISO by increased refiner housing pressure. The combination of $6.4 \mathrm{bar}(\mathrm{g})$ refiner housing pressure and addition of $0.6 \%$ sodium sulfite was found to be an interesting combination to increase wood softening during refining. This combination led to increased tensile index and reduced shives content, without darkening the pulp or reducing light scattering at certain specific electric energy consumption, Table 3.

The addition of sodium sulfite and increased refining temperature increased tensile index of pulps at certain SEC, Fig 4a. The increase in tensile index would enable a reduction in SEC of $\sim 380 \mathrm{kWh} / \mathrm{bdt}(18-22 \%)$ to equal tensile index when pulps are produced with $1.2 \%$ addition of sodium sulfite and a refiner housing pressure of $6.4 \mathrm{bar}(\mathrm{g})$, compared with the standard process without addition of sodium sulfite and $4.6 \mathrm{bar}(\mathrm{g})$ refiner housing pressure. However, it would not be possible to reduce SEC by these process modifications alone without a large reduction in the light scattering coefficient, Fig 9.

One way to be able to utilize increased refining temperature and sulfite addition to reduce energy consumption without reducing light scattering of the paper would be to combine these process modifications with an increased addition of filler at the paper machine. An increase in filler content of paper normally increases the light scattering coefficient and reduces the tensile index (Mohlin, Olander 1986). Therefore in order to increase the filler content of a paper without getting too low tensile index, the tensile index of the pulp used must be higher. The effect of such an implementation could both be seen as a reduction in refining energy per bdt of pulp and an even larger reduction in refining energy per bdt of paper, since less amount of pulp would be used per bdt of paper. 
Table 3 - Pulp properties interpolated to a total specific energy consumption of $1900 \mathrm{kWh} / \mathrm{bdt}$ for different refiner housing pressures and sodium sulfite doses.

\begin{tabular}{lcccccc}
\hline Sodium sulfite, \% & 0 & 0 & 0.6 & 0.6 & 1.2 & 1.2 \\
Pressure, bar(g) & 4.6 & 6.4 & 4.6 & 6.4 & 4.6 & 6.4 \\
\hline Tensile index, Nm/g & 44.6 & 47.0 & 48.7 & 52.9 & 52.8 & 56.4 \\
S460, $^{2} / \mathrm{kg}$ & 55.2 & 55.5 & 54.5 & 55.4 & 52.0 & 53.9 \\
Brightness, \% ISO & 61.5 & 61.1 & 63.6 & 63.5 & 64.5 & 64.2 \\
Shives, \#/g & 383 & 339 & 256 & 206 & 203 & 220 \\
\hline
\end{tabular}

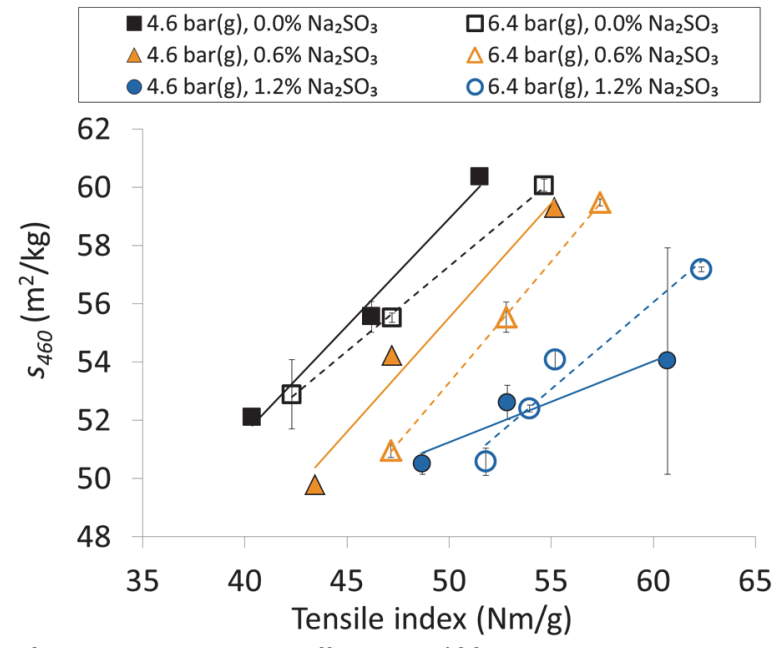

Fig 9 - Light scattering coefficient at $460 \mathrm{~nm}$ vs. tensile index.

Another way to utilize increased refining temperature and sulfite addition to reduce the energy consumption without reducing light scattering would be to combine these process modifications with increase in refining intensity. It was earlier shown that chip impregnation with sodium sulfite together with increased refining intensity could reduce the energy consumption by $15 \%$ while preserving both tensile strength and light scattering of the pulp, when applied at the lower refiner housing pressure (Nelsson et al. 2014).

\section{Conclusions}

Both addition of sodium sulfite to chip impregnation and increased refiner housing pressure reduced the refiner disc gap at constant specific energy consumption (SEC) indicating an increased wood softening. The sulfonate contents of pulps were $0.12 \%$ and $0.29 \%$ as $\mathrm{Na}_{2} \mathrm{SO}_{3}$ equivalents for the addition of $0.6 \%$ and $1.2 \%$ sodium sulfite, respectively.

The addition of $1.2 \%$ sodium sulfite increased tensile index by $8.6 \mathrm{Nm} / \mathrm{g}$ and increasing the refiner housing pressure (from 4.6 to $6.4 \mathrm{bar}(\mathrm{g})$ ) increased tensile index by $3.2 \mathrm{Nm} / \mathrm{g}$. The combined increase $(\sim 12 \mathrm{Nm} / \mathrm{g})$ was similar to the effect of increasing SEC by $380 \mathrm{kWh} / \mathrm{bdt}$ $(18-22 \%)$, when comparing pulps at equal tensile index.

Tensile index correlated with the percentage of fibers (>30 mesh) with high degree of delamination/internal fibrillation, which indicate the importance of fiber flexibility and collapsibility for the increase in tensile index of mildly sulfonated pulps.

The addition of sodium sulfite reduced the shives content significantly, whereas increased refiner housing pressure did not.
The addition of sodium sulfite $(0.6$ and $1.2 \%)$ increased brightness of pulps by about 2 and $3 \%$ ISO, respectively, by reducing the light absorption of sulfonated pulps. The increased refining temperature led to minor reductions in brightness $(\leq 0.4 \%$ ISO $)$ due to an increase in light absorption. Chromophores with absorption maxima at 490-500 $\mathrm{nm}$ were removed when sodium sulfite was charged indicating removal of ortho-quinones. At a higher sodium sulfite charge $(1.2 \%)$, chromophores with an absorption maxima at about $390 \mathrm{~nm}$ was additionally removed probably due to removal of coniferaldehyde and/or para-qunonoid structures.

The light scattering coefficient at constant tensile index was lower for pulps produced with increased refining temperature and addition of sodium sulfite. An implementation together with increased filler content in paper or increased refining intensity could, however, probably enable production of paper with similar tensile index and light scattering coefficient at lower SEC.

\section{Acknowledgements}

This study was performed within the "E2MP research profile" at Mid Sweden University, Sundsvall, Sweden and has been funded by Holmen, Valmet and the Swedish Knowledge Foundation. We would like to give special thanks to Geoffrey Daniel and Dinesh Fernando at SLU for performing the Simon's staining analyses and to Mats Rundlöf for helping with interpretation of optical data. Our warm thanks to all other who have helped with the work presented in this paper.

\section{Literature}

Atack, D., Heitner, C. and Stationwala, M.I. (1978): Ultra high yield pulping of eastern black spruce, Svensk Papperstidning 81(5), 164-176.

Axelson, P. and Simonson, R. (1982): Thermomechanical pulping with low addition of sulfite. 1. Effects of mild sulfite treatment of spruce chips prior to defibration, Svensk Papperstidning 85(15), R132-R139.

Becker, H., Höglund, H. and Tistad, G. (1977): Frequency and temperature in chip refining, Paperi Puu 59(3), 123-126, 129-130.

Engberg, B.A., Logenius, L. and Engstrand, P. (2014): Mechanical properties of sulphonated wood in relation to wing refiner properties. Int. Mech. Pulp. Conf., Helsinki, Finland, June 2-5, Paper Engineers' Association (PI), Espoo, Finland, 4 pp.

Fernando, D. and Daniel, G. (2010): Characterization of spruce thermomechanical pulps at the fiber cell wall level: a method for quantitatively assessing pulp fiber development using Simons' stain, Tappi J. 9(10), 47-55.

Fernando, D., Muhić, D., Engstrand, P. and Daniel, G. (2011): Fundamental understanding of pulp property development under different thermomechanical pulp refining conditions as observed by a new Simons' staining method and SEM observation of the ultrastructure of fibre surfaces, Holzforschung 65(6), 777-786.

Fernando, D., Gorski, D., Sabourin, M. and Daniel, G. (2013): Characterization of fiber development in high- and lowconsistency refining of primary mechanical pulp, Holzforschung 67(7), 735-745. 
Gellerstedt, G. (2009): Mechanical pulping chemistry. In: Ek, M., Gellerstedt, G. and Henriksson, G. (eds.), Volume 2, Pulping Chemistry and Technology, Walter de Gruyter GmbH \& Co., Berlin, Germany, pp. 41-64.

Gellerstedt, G. (2010): Chemistry of pulp bleaching. In: Heitner, C., Dimmel, D.R. and Schmidt, J.A. (eds.), Lignin and Lignans: Advances in Chemistry, CRC Press, Boca Raton, Florida, FL, USA, pp. 393-438.

Hon, D.N.-S. and Glasser, W. (1979): On possible chromophoric structures in wood and pulps - A survey of the present state of knowledge, Polym. Plast. Technol. Eng. 12(2), 159-179.

Höglund, H. and Wilhelmsson, K. (1993): The product must determine the choice of wood type in mechanical pulping. Int. Mech. Pulp. Conf., Oslo, Norway, June 15-17, Technical Association of the Norwegian Pulp and Paper Industry, Oslo, Norway, pp. 1-22.

Höglund, H., Bäck, R., Falk, B. and Jackson, M. (1997): Thermopulp - A new energy-efficient mechanical pulping process, Pulp Paper Can. 98(6), 82-89.

Irvine, G.M. (1985): The significance of the glass-transition of lignin in thermomechanical pulping, Wood Sci. Technol. 19(2), 139-149.

Johansson, L., Peng, F. and Simonson, R. (1997): Effects of temperature and sulfonation on shear deformation of spruce wood, Wood Sci. Technol. 31(2), 105-117.

Karlsson, A., Enberg, S., Rundlöf, M., Paulsson, M. and Edström, P. (2012): Determining optical properties of mechanical pulps, Nord. Pulp Paper Res. J. 27(3), 531-541.

Kubelka, P. and Munk, F. (1931): Ein Beitrag zur Optik der Farbanstriche, Z. Tech. Phys. 12(11a), 593-601.

Kubelka, P. (1948): New contributions to the optics of intensely light-scattering materials. Part 1., J. Opt. Soc. Am. 38(5), 448457.

Lundquist, K., Parkås, J., Paulsson, M. and Heitner, C. (2007): Reactions of lignin chromophores of the enal and enone types with sulfite, Bioresources 2(3), 334-350.

McDonald, D., Miles, K. and Amiri, R. (2004): The nature of the mechanical pulping process, Pulp Paper Can. 105(8), 2732.

Mohlin, U.-B. and Olander, K. (1986): The influence of mechanical pulp quality on the properties of filler-containing papers, Nord. Pulp Paper Res. J. 1(4), 44-51.

Muhić, D., Sundström, L., Sandberg, C., Ullmar, M. and Engstrand, P. (2010): Influence of temperature on energy efficiency in double disc chip refining, Nord. Pulp Paper Res. J. 25(4), 420-427.

Nelsson, E., Sandberg, C., Svensson-Rundlöf, E., Muhić, D., Rohdén, L., Engberg, B. and Engstrand, P. (2014): Improved energy efficiency in thermomechanical pulping through cooptimization of intensity by segment design and wood softening by sulfonation. Int. Mech. Pulp. Conf., Helsinki, Finland, June 25, Paper Engineers' Association (PI), Espoo, Finland, 4 pp.

Nelsson, E., Sandberg, C., Svensson-Rundlöf, E., Engstrand, P., Fernando, D. and Daniel, G. (2015): Low dosage sulfite pretreatment in a modern TMP-line, Nord. Pulp Paper Res. J. 30(4), 591-598.
Norgren, S., Höglund, H. and Bäck, R. (2004): Irreversible long fibre collapse at high temperature TMP reject refining initial studies, Pulp Paper Can. 105(7), 47-51.

Norrström, H. (1969): Light absorbing properties of pulp and pulp components. Part 2. Sulfite pulp, Svensk Papperstidning 72(2), 32-38.

Rundlöf, M. and Bristow, J.A. (1997): A note concerning the interaction between light scattering and light absorption in the application of the Kubelka-Munk equations, J. Pulp Paper Sci. 23(5), J220-J223.

Sabourin, M., Xu, E., Cort, B., Boileau, I. and Waller, A. (1997): Optimizing residence time, temperature and speed to improve TMP pulp properties and reduce energy, Pulp Paper Can. 98(4), 38-45.

Salmén, N.L. and Fellers, C. (1982): The fundamentals of energy consumption during viscoelastic and plastic-deformation of wood, Pulp Paper Can. 83(12), TR93-TR99.

Stone, J.E., Scallan, A.M. and Abrahamsson, B. (1968): Influence of beating on cell wall swelling and internal fibrillation, Svensk Papperstidning 71(19), 687-694.

Westermark, U., Samuelsson, B., Simonson, R. and Pihl, R. (1987): Investigation of a selective sulfonation of wood chips Part 5. Thermomechanical pulping with low addition of sulfite, Nord. Pulp Paper Res. J. 2(4), 146-151.

Yu, X.C., Minor, J.L. and Atalla, R.H. (1995): Mechanism of action of simons stain, Tappi J. 78(6), 175-180.

Zhang, L. and Gellerstedt, G. (1998): Quinone chromophores and their contribution to photo-yellowing in lignin. 5th European Workshop on Lignocellulosics and Pulp, Aveiro, Portugal, August 30 - September 2, University of Aveiro, Aveiro, Portugal, pp. 285-289.

Östberg, G. and Salmén, L. (1988): Effects of sulfonation on properties of different cell wall layers, Nord. Pulp Paper Res. J. 3(1), 8-12.

Manuscript received March 23, 2016 Accepted January 24, 2017 


\section{Appendix 1}

The regression function in Microsoft Excel 2010 was used to produce a multiple linear regression model with tensile index as dependent variable and specific energy consumption (SEC), refiner housing pressure and sodium sulfite addition as independent variables. The summary statistics for this model is shown below. Tensile index was measured twice for each pulp and both measurements were used in the model. Two of the 38 tensile index measurements showed large deviation from the model and from the second measurement of the same pulp. These two measurements were considered to be outliers and were not included in the model.

\begin{tabular}{ll} 
SUMMARY OUTPUT & \\
\hline Regression Statistics & \\
\hline Multiple R & 0.982794425 \\
R Square & 0.965884882 \\
Adjusted R Square & 0.96268659 \\
Standard Error & 1.171930482 \\
Observations & 36 \\
\hline
\end{tabular}

ANOVA

\begin{tabular}{lllllll}
\hline & $d f$ & $S S$ & $M S$ & $F$ & Significance $F$ \\
\hline Regression & 3 & 1244.320248 & 414.7734162 & 302.0001875 & $1.5295 \mathrm{E}-23$ & \\
Residual & 32 & 43.94947376 & 1.373421055 & & \\
Total & 35 & 1288.269722 & & & & \\
\hline & Coefficients & Standard Error & $t$ Stat & $P$-value & Lower 95\% & Upper 95\% \\
\hline & -14.25753545 & 2.58370036 & -5.518261976 & $4.39664 \mathrm{E}-06$ & -19.52036087 & -8.99471004 \\
Intercept & 0.030959467 & 0.00133395 & 23.20887217 & $1.37471 \mathrm{E}-21$ & 0.028242301 & 0.033676634 \\
Total SEC (kWh/bdt) & 3.199604959 & 0.392204257 & 8.158006699 & $2.56419 \mathrm{E}-09$ & 2.40071103 & 3.998498889 \\
Refiner housing pressure & $(4.6$ bar(g)=0; $6.4=1)$ & 0.403328361 & 17.79121896 & $3.73431 \mathrm{E}-18$ & 6.354150205 & 7.99725618 \\
$\mathrm{Na}_{2} \mathrm{SO}_{3}$ added $(\%)$ & 7.175703192 & & & &
\end{tabular}

\begin{tabular}{lll}
\hline Change in process parameter & Increase in tensile index $(\mathrm{Nm} / \mathrm{g})$ & Reduction in SEC to certain tensile index (kWh/bdt) \\
\hline $100 \mathrm{kWh} / \mathrm{bdt}$ & $3.1( \pm 0.27)$ & \\
4.6 to $6.4 \mathrm{bar}$ & $3.2( \pm 0.8)$ & $100(70-150)$ \\
$1.2 \% \mathrm{Na}_{2} \mathrm{SO}_{3}$ added & $8.61( \pm 0.99)$ & $280(220-340)$ \\
4.6 to 6.4 bar \& $1.2 \% \mathrm{Na}_{2} \mathrm{SO}_{3}$ & $11.81( \pm 1.78)$ & $380(290-490)$ \\
added & &
\end{tabular}

